2016-03

\title{
Use and perception of collars for companion cats in New Zealand.
}

\author{
Harrod, M
}

http://hdl.handle.net/10026.1/12085

$10.1080 / 00480169.2015 .1110064$

N Z Vet J

All content in PEARL is protected by copyright law. Author manuscripts are made available in accordance with publisher policies. Please cite only the published version using the details provided on the item record or document. In the absence of an open licence (e.g. Creative Commons), permissions for further reuse of content should be sought from the publisher or author. 


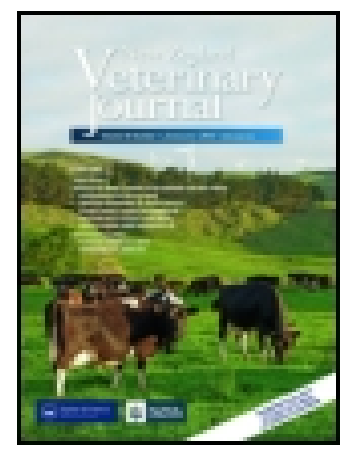

New Zealand Veterinary Journal

ISSN: 0048-0169 (Print) 1176-0710 (Online) Journal homepage: http://www.tandfonline.com/loi/tnzv20

\section{Use and perception of collars for companion cats in New Zealand}

\section{Harrod, A.J. Keown \& M.J. Farnworth}

To cite this article: M. Harrod, A.J. Keown \& M.J. Farnworth (2015): Use and perception of collars for companion cats in New Zealand, New Zealand Veterinary Journal, DOI: 10.1080/00480169.2015.1110064

To link to this article: http://dx.doi.org/10.1080/00480169.2015.1110064

View supplementary material ¿ Accepted author version posted online: 05
Nov 2015.

Submit your article to this journal ¿

Q View related articles $\widetilde{C}$

View Crossmark data $\nearrow$ 
Publisher: Taylor \& Francis \& New Zealand Veterinary Association

Journal: New Zealand Veterinary Journal

DOI: $10.1080 / 00480169.2015 .1110064$

\section{Short Communication}

Use and perception of collars for companion cats in New Zealand

\section{Harrod*, AJ Keown ${ }^{\dagger \S}$, MJ Farnworth**}

*Animal Welfare and Biodiversity Research Group, Department of Natural Sciences, Unitec Institute of Technology, Private bag 92025, Auckland 1025, New Zealand.

$\dagger$ Institute of Veterinary, Animal and Biomedical Sciences, Massey University, Private Bag 11222, Palmerston North 4442, New Zealand.

*Current Address: Biological Sciences, Plymouth University, 426 Portland Square, Drake Circus, Devon, PL4 8AA, United Kingdom.

${ }^{\S}$ Author for correspondence. Email: ashkeown@gmail.com

\section{Abstract}

AIMS: To investigate the use and utility of collars for companion cats in New Zealand, and to explore public perception of collar use

METHODS: An online questionnaire was distributed using emails and social media to members of the general public in New Zealand. The questionnaire collected details of respondents, cat ownership status, and responses to a number of questions regarding collar use in cats.

RESULTS: A total of 511 responses were collected. Of these, 393/511 (76.9\%) reported owning $\geq 1$ cat at the time of survey, and 141/393 (35.9\%) stated that $\geq 1$ of their cats wore collars and 211/393 $(53.7 \%)$ had $\geq 1$ of their cats micro-chipped. Of the respondents with a pet cat, 351/393 (89.3\%) allowed their cats some outdoor access. Respondents mainly used collars for identification and to reduce predation. Reasons for not using collars included cat intolerance of collars, repeated collar loss and concern over collar safety. Differences were found between cat owners and non-owners regarding whether they agreed that cats were important for pest control (43vs. $25 \%, \mathrm{p}<0.001)$; that not all cats will tolerate collars ( $81 v s .64 \%, \mathrm{p}<0.001)$; that cats should be kept indoors at night (37 vs. $58 \%, \mathrm{p}<0.001)$; or disagreed that well fed cats will not catch birds (60vs. $70 \%, \mathrm{p}=0.04)$; and disagreed that a cat without a collar was likely to be a stray ( $85 v s .76 \%, \mathrm{p}<0.001)$. Respondents 
most trusted veterinarians and the Society for the Prevention of Cruelty to Animals as sources of pet care information.

CONCLUSIONS: Collar use within this sample of cat owners in New Zealand appeared to be low, with more using microchips for identification. The majority of cat owners in this study indicated their cats had some outdoor access, with collars being used for cat identification and to reduce hunting behaviour. Significant differences existed in opinions on cat management between cat owners and non-owners in this study. It should be noted that this preliminary exploration was based on a self-selected group of respondents and so results and conclusions cannot be extrapolated to the wider population.

RELEVANCE: As the most trusted source of information about pet care, an enhanced understanding of cat ownership and management may be of use to veterinarians to promote responsible pet ownership and to develop national policies and practices to improve cat welfare. KEY WORDS: Animal welfare, cat, collar, identification, veterinary services

SPCA Society for the Prevention of Cruelty to Animals,

\section{Introduction}

The domestic cat population in New Zealand has been estimated to be approximately 1.4 million owned animals, and approximately $48 \%$ of households in New Zealand are reported to own a cat (MacKay 2011). This estimate excludes stray cats and, within Auckland, areas of high human population density have been shown to have particularly high densities of stray cats (Aguilar and Farnworth 2012,2013). Stray and owned cats are largely indistinguishable and are likely to have a complex interaction which perpetuates New Zealand's cat population. Given the body of evidence demonstrating a strong bond between cats and their owners (Staats et al. 2008; Sable 2013), companion cats, and therefore urban cat populations in general, are likely to remain part of the complex ecology of New Zealand for the foreseeable future.

Free-roaming cats may experience numerous hazards in the outdoor environment, including traffic accidents and fighting injuries (Loyd et al. 2013). Becoming lost is another of these risks and lost cats are less likely to be reunited with their owners than dogs, in part due to a lack of routine identification (Lord et al. 2007a; Weiss et al. 2012). Proper identification is also useful for contacting owners in the event of emergency veterinary treatment, where poor animal identification 
may delay necessary interventions and reduce the likelihood of a positive outcome (Slater et al. 2012).

Classifying cats as feral, stray, or owned and then differentiating between these groups is a task fraught with complexities (Farnworth et al. 2010a, b). Collars may be a useful means of negating the difficulties in differentiation of owned and unowned cats, as collars have been reported to be the most efficient method of visual identification for animals (Lord et al. 2007a, b). However collars are prone to loss, and public perception about the safety of collars may deter cat owners from using them (Lord et al. 2010; Calver et al. 2013). Microchips may be considered to be a safer, more reliable and permanent means of animal identification, however microchips are reported to be used even less frequently than collars (Lord et al. 2009, 2010; Slater et al. 2012).

Urban cats are known to be predators of wildlife in New Zealand (Gillies and Clout 2003; Flux 2007) and may have significant effects on both native and non-native urban bird species (Baker et al. 2008; van Heezik et al. 2010). Improved collar usage for cats may improve uptake of huntingdeterrent devices, such as bells, which have been demonstrated to reduce the hunting success of cats (Nelson et al. 2005; Calver et al. 2007; Gordon et al. 2010). Regular use of collars with antipredation devices may mitigate the impact of cats on native and non-native fauna in New Zealand (Farnworth et al. 2010a; Calver et al. 2011; Calver and Thomas 2011). Thomas et al. (2012) reported that cat owners were less likely than non-cat owners to consider collar-mounted antipredation devices to be acceptable, which may explain why respondents to a New Zealand survey stated that of those cats wearing collars, only half of them had bells attached (Farnworth et al. 2010a).

The aim of this preliminary study was to investigate the use and utility of collars for companion cats in New Zealand, and to explore public perception of collar use.

\section{Materials and Methods}

\section{Survey}

Data on cat ownership, use of collars, and perceptions of collar use were sought via an anonymous online survey. The target population was a sample of the general public of New Zealand, and the survey was randomly distributed via e-mail to contacts at the Society for the Prevention of Cruelty to Animals (SPCA), Unitec, University of Auckland, Victoria University, University of Otago, Lonely Miaow (Auckland, NZ), The Animal Sanctuary (Warkworth, NZ), and NZ Landcare Trust (Hamilton, NZ), and social media using an initial posting of the survey link on personal Facebook pages, Unitec Marketing, and Unitec Bachelor of Applied Science pages. Participants were asked to 
participate, and to further distribute the survey. The survey remained open from 7-29 August 2013, and responses were gathered from adult (18 years and over) New Zealand residents. The survey consisted of 14 questions, as shown in Supplementary Table 1. ${ }^{1}$ Data gathered included age, gender, area of residence, cat-ownership status, and management of any owned cats. Respondents were also asked to indicate their level of agreement with a number of statements regarding cats and collar use. Responses were on a 5-point Likert scale (Likert 1932) ranging from 'strongly agree' to 'strongly disagree'.

The research was approved by the Unitec Research Ethics Committee, Auckland, New Zealand (UREC Registration Number: 2011-1152).

\section{Statistical Analyses}

Results were analysed using SPSS/PSAW 21 statistical software (IBM Inc., Chicago, IL, USA). $\chi^{2}$ tests were used on contingency tables to explore differences between rurat and urban cat owners regarding collar use, and attitudes toward cats for pest control, and between cat owners and nonowner attitudes towards cats and collar use. Responses on a 5-point Likert scale were categorised as strongly agree/agree, neither agree nor disagree, and disagree/strongly disagree, for analysis in order to satisfy the assumptions of the statistical test, as were the categories of residence, categorised as inner city/urban, and semi-rural/rural.

\section{Results}

A total of 511 responses were collected. The demographics of the respondents are shown in Table 1. Of the respondents, $393 / 511(76.9 \%)$ reported owning $\geq 1$ cat at the time of survey. There was a strong bias towards female respondents and cat owners with 37/68 (54.4\%) male respondents stating they own a cat, compared with $354 / 440(80.5 \%)$ female respondents $(\mathrm{p}<0.001)$.

Responses regarding cat ownership and collar use are summarised in Table 1. Of the cat owning respondents, 141/393 (35.9\%) stated at least some of their cats wore collars. More Inner city/urban cat owners $(97 / 312 ; 31.1 \%)$ than semi-rural/rural cat owners $(13 / 74 ; 17.6 \%)$ had cats that wore a collar ( $\mathrm{p}=0.021)$. Of the respondents who reported owning a cat, $211 / 391(54.0 \%)$ had $\geq 1$ of their cats micro-chipped; $211 / 390$ (54.0\%) allowed their cats outdoor access at all times, and 139/374 $(37.2 \%)$ thought their cat rarely left their property. In addition, 174/378 (46.0\%) respondents felt confident their cat was safe whilst free-roaming.

Amongst all respondents, 283/486 (58.2\%) agreed collars with bells, or other deterrent devices reduced the number of animals and birds cats catch or kill. The reasons given by cat owners for and

${ }^{1}$ DOI: [production editor to insert] 
against collar use are presented in Table 2. Respondents most often used collars for identification, and to reduce predation of birds and other animals. Barriers to collar use as perceived by respondents were: cat intolerance of collars, repeated collar loss, and concern over collar safety.

There were differences in attitude between cat owners and non-owners regarding whether cats were important for pest control $(\mathrm{p}<0.001)$; whether cats will tolerate collars $(\mathrm{p}<0.001)$; whether being well fed influences cat hunting behaviour $(\mathrm{p}=0.04)$; whether cats should be kept indoors at night $(\mathrm{p}<0.001)$; and whether a cat without a collar was likely to be a stray $(\mathrm{p}<0.001)$. The distribution of responses is shown in Figure 1.

When asked which sources of pet care information were most trusted, respondents most often identified veterinarians $(389 / 511 ; 76.1 \%)$ and the SPCA $(42 / 511 ; 8.2 \%)$.

\section{Discussion}

The method of online survey distribution utilised in this study creates a number of important limitations including a response bias in favour of those with access to the internet, and (most likely) with an interest in animal welfare and/or cats. The respondents were assumed to be over 18 years old, and New Zealand residents, however there was no way to verify this.

The female bias in responses is unsurprising, as female response bias to online questionnaires has been previously demonstrated (Stieger et al. 2007), and the large proportion of female cat owners is consistent with the other studies (Murray et al.2010; Westgarth et al. 2010).

The low percentage of respondents reporting cat collar use is consistent with the findings of Farnworth et al. (2010a). Micro-chipping appeared to be more commonplace than collar use, and may be a preferable method of cat identification for cat owners in New Zealand. This differs from other studies, where collars were reported to be utilised more frequently than microchips (Lord et al. 2009, 2010)

The 37\% of owners who felt their cats rarely leave their own property almost certainly underestimated the true range of their cats (Barratt 1997; Horn et al. 2011; Wierzbowska et al. 2012). Nearly $50 \%$ of respondents indicated they felt confident their cat was safe whilst freeroaming, which suggests many owners may be unaware of the many risks cats face while freeroaming. Cat owners were also more likely to disagree with statements suggesting cats be confined. These observations suggest a cat's ability to roam freely may be perceived as quite important to cat owners. The difference in opinion between cat owners and non-owners seen in this study indicates further research into the values and motivations of cat owners is warranted. 
The majority of respondents agreed that collar-mounted devices reduce predation, and many reported using collars for such a purpose. Despite this, many agreed that 'cats play an important role in the control of pests' and cat owners were more likely to agree than non-cat owners. There may be some dissonance between the perceived value of cats for their ability to hunt and control pests, and the desire to reduce hunting behaviour. Unfortunately the current study did not gather data on use of collar mounted devices, so no further insight into such devices can be gleaned.

Whilst only a preliminary investigation, this study has yielded interesting results which indicate collars are not widely used by this sample of cat owners in New Zealand, and microchips may be more readily adopted as a means of cat identification. Most cats owned by respondents to this study had outdoor access; and respondents mainly used collars to identify their animals and to reduce hunting behaviour. Owners and non-owners within this study sample appear to have different opinions on several aspects cat management. As the most trusted sources of information about pet care according to respondents, veterinarians and the SPCA are in a privileged position to promote positive states of welfare for companion cats through client education and legislative change.

\section{References}

Aguilar GD, Farnworth MJ. Stray cats in Auckland, New Zealand: Discovering geographic information for exploratory spatial analysis. Applied Geography 34, 230-8, 2012

Aguilar GD, Farnworth MJ. Distribution characteristics of unmanaged cat colonies over a 20 year period in Auckland, New Zealand. Applied Geography 37, 160-7, 2013

Barratt DG. Home range size, habitat utilisation and movement patterns of suburban and farm cats Felis catus. Ecography 20, 271-80, 1997

Calver MC, Thomas SR. Effectiveness of the Liberator $^{\mathrm{TM}}$ in reducing predation on wildlife by domestic cats. Pacific Conservation Biology 16, 244-50, 2011

Calver M, Thomas S, Bradley S, McCutcheon H. Reducing the rate of predation on wildlife by pet cats: The efficacy and practicability of collar-mounted pounce protectors. Biological Conservation 137, 341-8, 2007

Calver MC, Grayson J, Lilith M, Dickman CR. Applying the precautionary principle to the issue of impacts by pet cats on urban wildlife. Biological Conservation 144, 1895-901, 2011

Calver M, Adams G, Clark W, Pollock K. Assessing the safety of collars used to attach predation deterrent devices and ID tags to pet cats. Animal Welfare 22, 95-105, 2013 
Farnworth M, Campbell J, Adams N. Public awareness in New Zealand of animal welfare legislation relating to cats. New Zealand Veterinary Journal 58, 213-7, 2010a

Farnworth MJ, Dye NG, Keown N. The Legal Status of Cats in New Zealand: A Perspective on the Welfare of Companion, Stray, and Feral Domestic Cats (Felis catus). Journal of Applied Animal Welfare Science 13, 180-8, 2010b

Flux JE. Seventeen years of predation by one suburban cat in New Zealand. New Zealand Journal of Zoology 34, 289-96, 2007

Gillies C, Clout M. The prey of domestic cats (Felis catus) in two suburbs of Auckland City, New Zealand. Journal of Zoology 259, 309-15, 2003

Gordon J, Matthaei C, Van Heezik Y. Belled collars reduce catch of domestic cats in New Zealand by half. Wildlife Research 37, 372-8, 2010

Horn JA, Mateus-Pinilla N, Warner RE, Heske EJ. Home range, habitat use, and activity patterns of free-roaming domestic cats. The Journal of Wildlife Management 75, 1177-85, 2011

Likert R. A technique for the measurement of attitudes. Archives of Psychology, 140, 1-55, 1932

Lord LK, Wittum TE, Ferketich AK, Funk JA, Rajala-Schultz PJ. Search and identification methods that owners use to find a lost cat. Journal of the American Veterinary Medical Association 230, 217-20, 2007a

Lord LK, Wittum TE, Ferketich AK, Funk JA, Rajala-Schultz PJ. Search methods that people use to find owners of lost pets. Journal of the American Veterinary Medical Association 230, $1835-40,2007 b$

Lord LK, Ingwersen W, Gray JL, Wintz DJ. Characterization of animals with microchips entering animal shelters. Journal of the American Veterinary Medical Association 235, 160-7, 2009

Lord LK, Griffin B, Slater MR, Levy JK. Evaluation of collars and microchips for visual and permanent identification of pet cats. Journal of the American Veterinary Medical Association $237,387-94,2010$

Loyd K, Hernandez S, Abernathy K, Shock B, Marshall G. Risk behaviours exhibited by free roaming cats in a suburban US town. Veterinary Record 173, 295, 2013 
*MacKay J. Companion Animals in New Zealand. http://nzcac.org.nz/images/publications/nzcaccanz2011.pdf (accessed 15 July 2014). New Zealand Companion Animal Council Inc., Auckland, New Zealand, 2011

Murray J, Browne W, Roberts M, Whitmarsh A, Gruffydd-Jones T. Number and ownership profiles of cats and dogs in the UK. Veterinary Record 166, 163, 2010

Nelson S, Evans A, Bradbury R. The efficacy of collar-mounted devices in reducing the rate of predation of wildlife by domestic cats. Applied Animal Behaviour Science 94, 273-85, 2005

Sable P. The pet connection: an attachment perspective. Clinical Social Work Journal 41, 93 2013

Slater M, Weiss E, Lord L. Current use of and attitudes towards identification in cats and dogs in veterinary clinics in Oklahoma City, USA. Animal Welfare 21, 51, 2012

Staats S, Wallace H, Anderson T. Reasons for companion animal guardianship (pet ownership) from two populations. Society and Animals 16, 279-91,2008

Stieger S, Reips UD, Voracek M. Forced-response in online surveys: Bias from reactance and an increase in sex-specific dropout. Journal of the American Society for Information Science and Technology 58, 1653-60, 2007

Thomas RL, Fellowes MDE, Baker PJ. Spatio-temporal variation in predation by urban domestic cats (Felis catus) and the acceptability of possible management actions in the UK. PLoS ONE 7, e49369, 2012

van Heezik Y, Smyth A, Adams A, Gordon J. Do domestic cats impose an unsustainable harvest on urban bird populations? Biological Conservation 143, 121-30, 2010

Weiss E, Slater M, Lord L. Frequency of lost dogs and cats in the United States and the methods used to locate them. Animals 2, 301-15, 2012

Westgarth C, Pinchbeck G, Bradshaw J, Dawson S, Gaskell R, Christley R. Factors associated with cat ownership in a community in the UK. Veterinary Record 166, 354-7, 2010

Wierzbowska IA, Olko J, Hędrzak M, Crooks KR. Free-ranging domestic cats reduce the effective protected area of a Polish national park. Mammalian Biology-Zeitschrift für Säugetierkunde 77, 204-10, 2012 
* Non-peer-reviewed

Submitted 2 October 2014

Accepted for publication 7 October 2015

First published online [insert date]

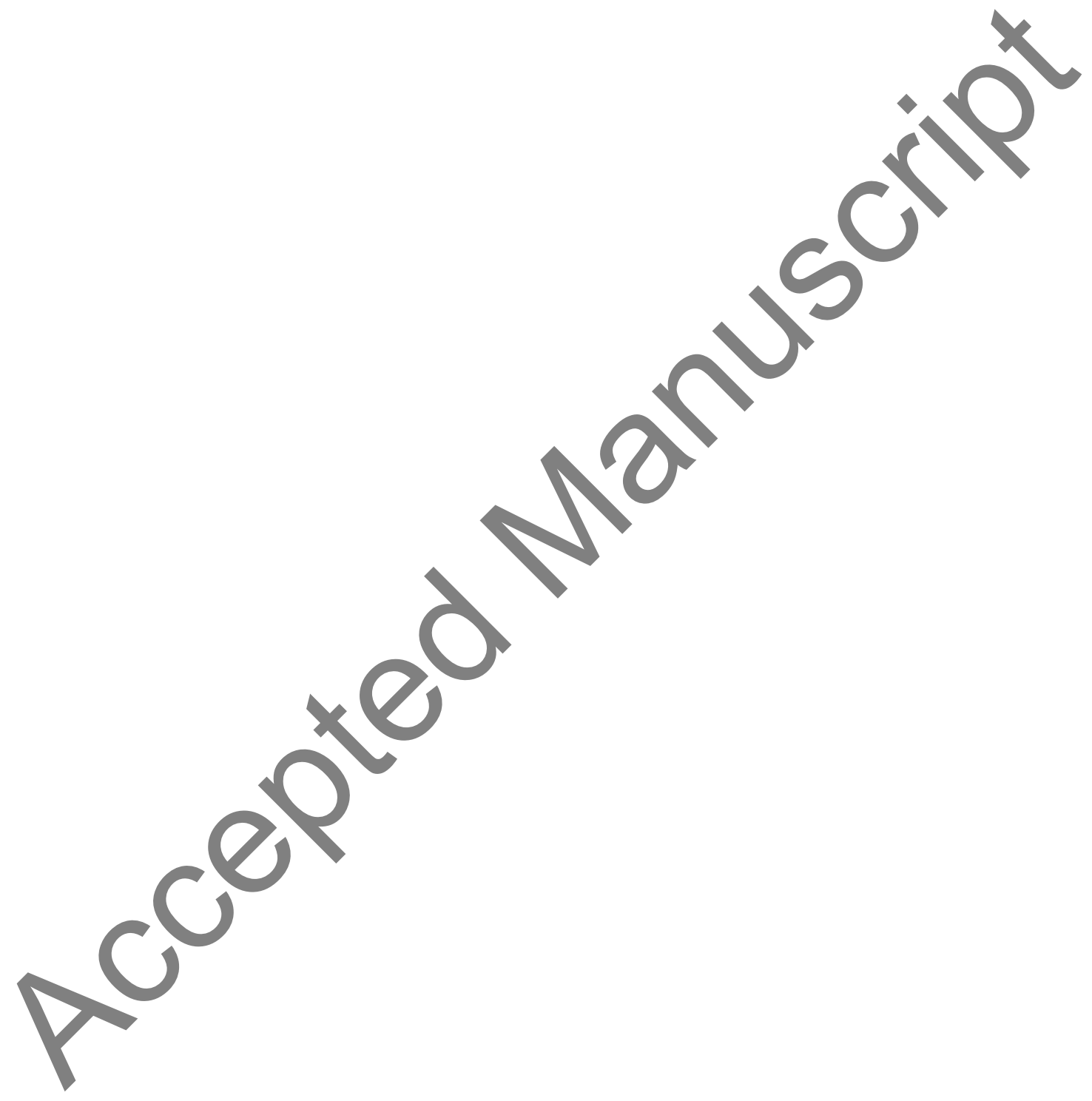


Table 1. Description of respondents to a survey of a sample of the New Zealand public regarding perceptions of cats and collar use, with information about the management of cats by those who were cat owners.

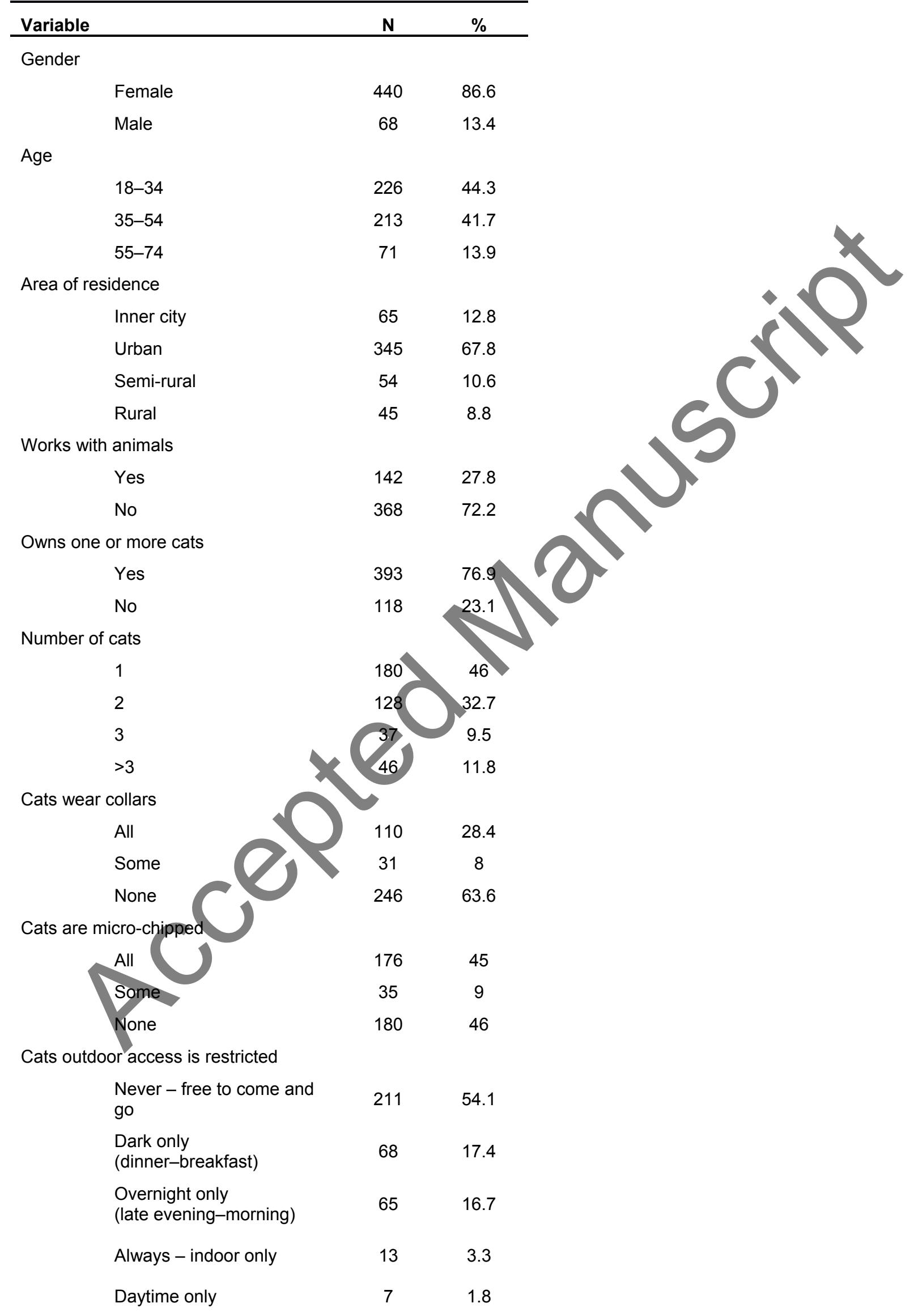




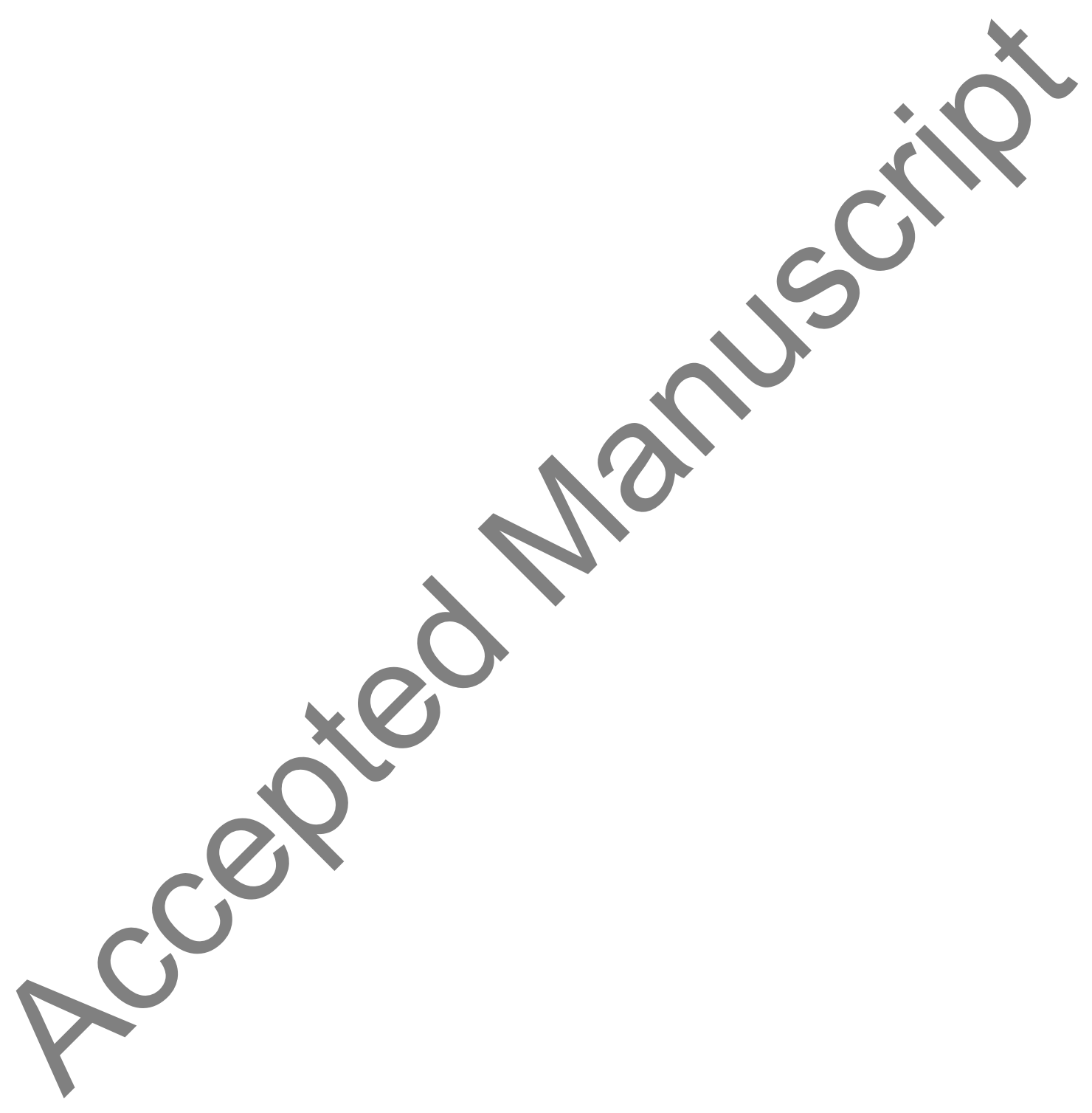


Table 2. Responses to a survey of a sample of the New Zealand public regarding perceptions of cats and collar use by cat owners $(n=393)$, showing reasons why collars were or were not used by respondents. Note respondents could select as many reasons as they felt were applicable.

\begin{tabular}{|c|c|c|c|}
\hline Reasons collars used & $\mathbf{N}$ & Reasons collars not used & $\mathbf{N}$ \\
\hline Identification & 105 & $\begin{array}{l}\text { My cat keeps losing them/They need to be replaced } \\
\text { too often }\end{array}$ & 118 \\
\hline $\begin{array}{l}\text { To prevent them catching/killing } \\
\text { birds }\end{array}$ & 71 & My cat is intolerant of collars & 101 \\
\hline $\begin{array}{l}\text { To prevent them catching/killing } \\
\text { other animals }\end{array}$ & 40 & I think collars are unsafe & 88 \\
\hline Because they look great & 18 & $\begin{array}{l}\text { I've had a cat injured becau } \\
\text { collar/l have lost a cat due to }\end{array}$ & 63 \\
\hline Flea control & 17 & $\begin{array}{l}\text { I am happy for my cat to control pests a } \\
\text { home }\end{array}$ & 54 \\
\hline \multirow[t]{6}{*}{ Other } & 34 & $\begin{array}{l}\text { I don't believe collars are } \\
\text { hunting behaviour }\end{array}$ & 47 \\
\hline & & $\begin{array}{l}\text { My cat is micro-chipped } \\
\text { collar for identification }\end{array}$ & 35 \\
\hline & & vemed to bother my cat & 28 \\
\hline & & The bells/beepers on them are disruptive to us & 16 \\
\hline & & Too expen & 10 \\
\hline & & Other & 65 \\
\hline
\end{tabular}


Figure 1. Bar graph showing results of a survey of a sample of the New Zealand public regarding perceptions of cats and collar use, showing the responses of cat-owners $(n=393)$ and non-owners $(n=118)$ to the statements (1) Cats play an important role in controlling pest populations in New Zealand; (2) Not all cats will tolerate a collar; (3) Domestic cats who are well fed do not tend to catch many animals/birds; (4) I believe owners should always keep cats indoors overnight; (5) Cats not wearing collars are generally stray cats. Responses were categorised as: strongly agree/agree (dark grey bars), neither agree nor disagree (light grey bars) or disagree/strongly disagree (mid-grey bars).

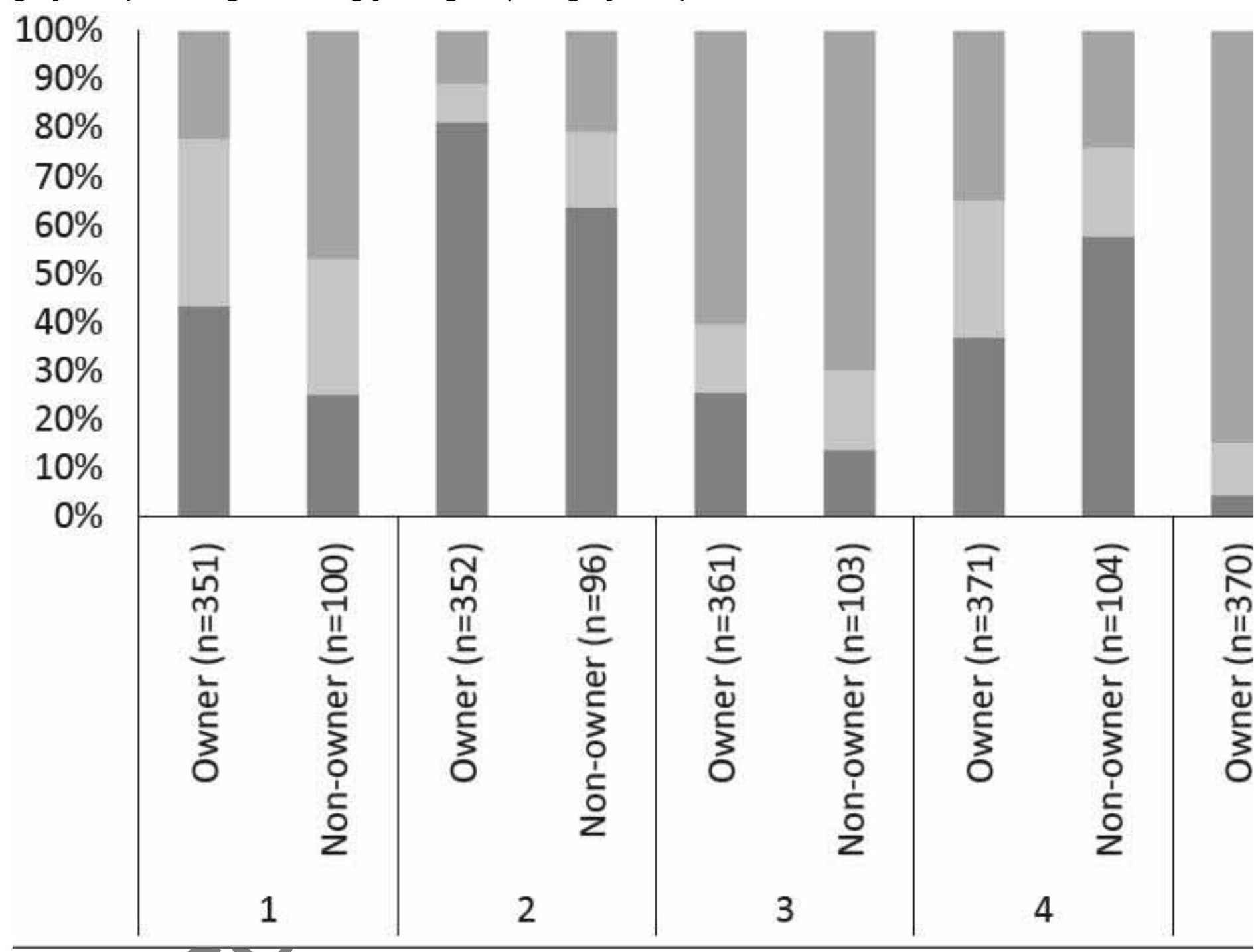

